Portland State University

PDXScholar

$5-24-2019$

\title{
The Relationship between Attachment Style and Hyperperceptions
}

Nolan E.G. Welch

Portland State University

Follow this and additional works at: https://pdxscholar.library.pdx.edu/honorstheses Let us know how access to this document benefits you.

\section{Recommended Citation}

Welch, Nolan E.G., "The Relationship between Attachment Style and Hyperperceptions" (2019). University Honors Theses. Paper 696.

https://doi.org/10.15760/honors.713

This Thesis is brought to you for free and open access. It has been accepted for inclusion in University Honors Theses by an authorized administrator of PDXScholar. Please contact us if we can make this document more accessible: pdxscholar@pdx.edu. 
The Relationship Between Attachment Style and Hyperperceptions

\title{
by
}

\section{Nolan Welch}

An undergraduate honors thesis submitted in partial fulfillment of the

\author{
requirements for the degree of \\ Bachelor of Science \\ in \\ University Honors \\ and \\ Communication
}

Thesis Adviser

Dr. Erin Spottswood

Portland State University 


\begin{abstract}
Three different attachment styles from previous research were examined in a closer context to see if they were predictive of hyperperceptions in romantic relationships while using social networking sites (SNS). The hyperperception model, a new communication concept, focuses on the over-attribution of others' relationships based on brief observations through SNS usage. Undergraduate communication students recruited from the Pacific North West and another university in the Midwest, with an active Facebook account, were sampled for this research. Participants responded to survey questions designed to test if hyperperceptions occurred in their romantic relationship from observations they made on SNSs. The participants' partners also needed an active Facebook account in order for the participant to take part in the study. Data analysis revealed that the participant attachment style did play a role in the development of hyperperceptions from their own observations on SNSs regarding their partner's relationship with others. Together, these findings suggest that the relationship between attachment style and hyperperceptions have reason to be explored further. These findings also suggest that attachment style may impact one's own perceptions surrounding relationships that they see on SNS platforms.
\end{abstract}

Keywords: attachment style, hyperperception, perception 
People are generally interested in the personal lives of those they share close relationships with (Muise, Christofides, \& Desmarais, 2013). As observers, this interest causes us to closely watch those in our close relationships out of that same high personal interest. The more we observe our close friends or romantic partners, the more likely we are to make observations about their lives, choices, and activities; we may perceive these people to be different than who we believe them to be. However, these perceptions are not always accurate. This is especially true and relevant on social networking sites (SNS). If someone was to see a brief interaction between two adults on a facebook post, where they exchange a friendly "hello!," and state that they very much miss seeing one and other, an observer may assume that they are good friends, have known each other for a long time, and are on good terms. In reality, it is possible that two may not have any interest in each other and have only been acquainted once in a physical faceto-face interaction. Exaggerated perceptions, such as the observer's in this hypothetical scenario, have been defined by Spottswood and Carpenter (Under Review) as "hyperperceptions," a communication concept and model that seeks to explain these over-attributions of other's SNS interactions.

The hyperperception model seeks to provide an explanation for these over-attributions, and why they may occur via SNS use. More specifically, Spottswood and Carpenter's (Under Review) hyperperception model focuses on the observer of an interaction on an SNS. However, one outside influencing factor on hyperperceptions may be one's attachment style. As posed by Hazan and Shaver (1987), attachment styles can reflect individual's feelings of finding it hard to get closer to others, feelings of extreme safety in their relationships, or extreme jealous when they find their significant other(s) doing things that do not meet their expectations in the relationship. While hyperperceptions look at over-attributions of observed SNS interactions more 
generally (based on the perceptions of the observer), attachment style may help explain which kinds of people are more prone to developing hyperperceptions about another's relationship(s) according to what they see on SNSs. More specifically, attachment style may predict when people develop hyperperceptions of their romantic partner's SNS interactions and relationships.

Within romantic relationships, it is not uncommon for a partner in the relationship to become concerned that their partner has interest in another person because of observed interactions between the two. However, an observer of these interactions may overattribute the strength of the relationship based on what they saw in that one situation. This, therefore, means that the relationship is perceived to be stronger than it really is based on the observer's perception. Interestingly enough, SNSs contributes to these quickly passed off judgements from brief observations.

With SNSs (such as Facebook, for example), friends, family, and romantic partners alike have access to each other's past and present on-site interactions. If a romantic partner was to become concerned over an observed interaction between their partner and another individual, they could use SNSs to potentially create a stronger rooted belief that their partner is pursuing or being pursued by another person or romantic rival. This study seeks to explore the relationship between the attachment styles and hyperperception phenomena in greater detail. We will first begin with a brief review of the literature to date on the relationship between SNS use and jealousy, hyperperceptions/the hyperperception model and attachment styles. Then, we will explicate how the hyperperception model considered alongside attachment style theory explains the relationship between SNS use and jealousy.

\section{Research Addressing the Relationship Between Jealousy/SNS}


Bodies of research have addressed the relationship between jealousy and SNS use long before the development of the hyperperception model. SNSs, such as Facebook, have had big impacts on relational management, and this is especially true for romantic couples experiencing romantic jealousy. Romantic jealousy can be broken down as threat, real or perceived, by a partner to their romantic relationship (including their goals and significant other) (Dainton \& Stokes, 2015). Misunderstanding a comment, post, or share from another's wall on Facebook may lead to feelings of a perceived threat or cause for concern (Dainton \& Stokes, 2015). These observations, which could actually be 'hyperperceptions,' may be more likely if one was to demonstrate "trait jealousy," which is a demonstration of jealousy across different situations and events (Dainton \& Stokes, 2015). Empirical data supports the belief/potential for romantic partners to find perceived threats or have cause for concern, as over $50 \%$ of college students claim to be using Facebook as a way to run surveillance on romantic partners (Marshall, Bejanyan, Castro, \& Lee, 2012). With the use of Facebook for surveillance of a romantic partner and/or information seeking, it is possible that a partner may find undesired answers through snooping around. Answers found from snooping may consist of secretive messages, or frequent conversations between their partner and another perceived threat that they do not want their partner talking to. This could be considered a clear relationship between jealousy and SNS use.

Fleuriet, Cole, and Guerrero's (2014) study provided more support in favor of a connection between jealousy and SNS use. Fleuriet et al. (2014) examined the different outcomes of messages on CMC platforms that had a potential to be jealousy-inducing. Fleuriet et al. (2014) is consistent with the findings of other studies, such as Dainton and Stokes (2015), that conclude one of the main purposes for regular Facebook users is relational maintenance/to keep tabs on one's romantic partner. Similar to the research of Fox, Warber, and Makstaller's (2013) 
study in regards to Facebook stalking, Fleuriet et al. (2014) explain that Facebook "lurking" (to view a page without commenting) is common amongst users as well.

One of the interesting points raised by Fleuriet et al. (2014) is the emotions that can be triggered from non-verbal cues found in CMC. This could be, in part, because non-verbal cues leave room for ambiguity, and those who dislike uncertainty may find themselves in uncomfortable/jealous positions (Fleuriet et al., 2014). While very common and utilized to date, emoticons, or frequently referred to today as "emojis," are a form of non-verbal communication that was tested in Fleuriet et al.'s (2014) study. Messages, such as, "It was really great seeing you last night," would have a suggestive emoji placed after the message (such as a wink face, "(:)") to see if it led to negative emotions in participants, which it did. This could be for a multitude of reasons, such as cultural meaning behind such an emoticon, or a personal interpretation of the message. However, the findings of Fleuriet et al. (2014) demonstrates the level of jealousy that can arise from the addition of an emoji/emoticon to a message on CMC. Regardless of the accuracy of the message's interpretation, making large generalizations of a relationship based on one message alone shows signs of hyperperception effects. These hyperperceptions could be impacted by a specific attachment style, such as one that leans towards personal/relational insecurity

Here, it is clearly shown that there is a connection between jealousy and SNS use that has been established in existing research, but the research observing this phenomena has yet to be rooted in a theoretical model that explicates the fundamental mechanisms behind why some, but not all, experience jealousy when they observe their romantic partners interact with other people on SNSs. This is the purpose of the hyperperception model, which will be described below. 


\section{The Hyperperception Model}

The hyperperception model, an extension of Walther's (1996) robust hyperpersonal model, examines an observer's perceptions of a relationship (or multiple relationships) based on interactions they have seen from others on an SNS platform. The hyperperception model has four key components: the channel, the sender, the receiver, and the feedback loop (Spottswood \& Carpenter, Under Review). The channel within the hyperperception model addresses the means in which hyperperceptions can occur. Spottswood and Carpenter (Under Review) explain that hyperperceptions are more likely to occur when an observer of an interaction has access to records of all interactions prior; something that is very accessible on SNS platforms. In addition, hyperperceptions are more likely to occur on/within channels that have positive posting and interaction norms (Utz, 2015), meaning that people are mainly positive and friendly in these spaces. This can lead to an observer only seeing positive interactions between a sender and receiver, and the false belief that those observations are indicative of the two interaction partners liking one and other. The second piece to the hyperperception model is the sender. As posed in the hyperperception model, the observer must have an interest in a specific sender's interactions on an SNS (Spottswood \& Carpenter, Under Review). Given that people in romantic relationships want to ensure their partner is being faithful (Muise, Christofides, \& Desmarais, 2013), it makes sense that they would observe the messages their partner "sends" to others on SNSs. The third component to the hyperperception model is the receiver. The receiver in the hyperperception model will be of interest to the observer, as they are receiving messages from the sender; the main person of interest (Spottswood \& Carpenter, Under Review). This, for example, may be a wife (the observer) taking an interest in the receiver (an ex-girlfriend) of her husband's (the sender) messages on Facebook. The hyperperception model does make claim to 
the fact that hyperperceptions are more likely to occur if the observer of the interaction(s) does not know the receiver well (Spottswood \& Carpenter, Under Review). Finally, the fourth and final component to the hyperperception model is the feedback loop. The feedback loop suggests that hyperperceptions may be more likely with continued observations of a sender's interactions with a receiver on an SNS.

These different parts work in conjunction with the main focus of the model, the observer, to help predict and explain why some but not all make over-attributions of their romantic partner's interactions with others on an SNS which in turn could increase the likelihood they will experience jealousy. In addition to research that has been conducted on the hyperperception model, preexisting research regarding attachment styles and what they pose for different individuals may further illuminate the occurrence of hyperperception phenomena. Depending on the attachment style an individual uses in their life, they may or may not be more likely to develop hyperperception effects on SNSs through brief observations. For this reason, it is important to consider the preexisting research on attachment styles.

\section{Attachment Styles}

Attachment theory, the foundation of attachment styles, was developed to address the impact of separating infants from their primary caregiver for lengthy periods of time (Hazan \& Shaver, 1987). Stemming from attachment theory, Hazan and Shaver (1987) describe the three attachment styles were developed to explain infant responses to being separated from their primary caregiver: the secure attachment style, the anxious/ambivalent attachment style, and the avoidant attachment style. In modern day, these attachment styles have been extended to other areas of research, such as romantic partners, and the definitions have been remolded 
(Simpson, 1990). Today, the secure attachment style entails that an individual would find that they were able to accept their romantic partner, despite their faults, and find that happy, friendly, and trusting are the most notable factors when experiencing love (Hazan \& Shaver, 1987). The anxious/ambivalent attachment style entails that individuals find that they see love as something requiring reciprocation from the other partner, with a high sexual attraction and jealousy level (Hazan \& Shaver, 1987). Lastly, the avoidant attachment style entails that individuals may find that they do not believe in fairy-tale love as seen in films and books, that love is not something to commonly last for a lifetime, and find themselves afraid of becoming close and intimate (Hazan $\&$ Shaver, 1987). Within this research, attachment styles are applied as the ways in which individuals respond to feelings of jealousy, concern, or potential threats in their romantic relationships/with their romantic partner.

When these three different attachment styles are taken into consideration in tandem with the Spottswood and Carpenter's (Under Review) hyperperception model, it is possible to see how certain attachment styles may be more predictive of hyperperception effects. For example, an anxious/ambivalent person may react very negatively and jealously to seeing their significant other having a conversation with another attractive person over Facebook comments, and thus create a hyperperception that the two are much closer than they really are (Hazan \& Shaver, 1987; Spottswood \& Carpenter, Under Review). These attachment styles have been expanded on in future research, however, Hazan \& Shaver's (1987) work was some of the first to address attachment styles and their impact on future relationships (specifically with parents and children in their study). Hazan and Shaver's (1987) attachment styles, while all different, do show clearly that certain attachment styles are more inclined to experience hyperperception effects than others. 
As stated, the attachment styles posed by Hazan and Shaver (1987) are different in how likely/inclined they are to contribute to helping an individual develop hyperperceptions. Individuals with a secure attachment style are much more trusting of their partner, as well as able to love them for their flaws (Hazan \& Shaver, 1987). This description suggests that they are far less likely to develop hyperperceptions around their partner's relationships with others because they trust their partner to be faithful to them (there is not need for jealousy). This is very different from the anxious/ambivalent attachment style, however. Anxious/ambivalent individuals may be more likely to develop hyperperceptions of their partner's SNS interactions with others because they are more jealous than the average individual (Hazan \& Shaver, 1987). Anxious/Ambivalent people are also fueled by a high sexual attraction to their romantic partners, and if that attraction is not reciprocated by their partner, anxious/ambivalent people may become more concerned or jealous of their partner's other relationships (Hazan \& Shaver, 1987). In some studies, such as Dainton and Stokes (2015), this may explain why some individuals were more likely to develop feelings of jealousy or cause for concern; their attachment style contributed to their feelings of jealousy. Other studies, such as Marshall et al.'s (2012) article on college students using Facebook as a means to survey their partner, may also be influenced by attachment style. Those with an anxious/ambivalent attachment style may be more prone to feelings of jealousy than those with secure or avoidant attachment styles, leading them to survey their partner due to potential hyperperceptions and feelings of jealousy. However, while attachment styles play a large role in understanding why individuals may develop hyperperception effects, it is important to note that this is not the case for all studies.

\section{How the Hyperperception Model and Attachment Styles Explain Preexisting Research}


The hyperperception model considered alongside attachment styles may offer an explanation for why romantic jealousy sometimes co-occurs with SNS use, including how each attachment style may lead to the development of hyperperception effects.

While Spottswood and Carpenter's (Under Review) hyperperception model does not discuss attachment style in its original description, attachment style may play an interesting role in whether or not hyperperceptions are more prone to being developed. In fact, it could be argued that attachment style is very predictive of whether or not hyperperceptions may occur. For example, individuals with an anxious/ambivalent attachment style may develop hyperperception effects (based on the above example) because their attachment style entails high levels of jealousy (Hazan and Shaver, 1987). If an anxious/ambivalent person felt that their partner had not been reciprocating a mutual level of attraction in recent days, but had spent time on SNS talking to other individuals, the anxious/ambivalent individual may observe this and become jealous. This jealousy may lead to hyperperception effects, such as their partner has more interest in their shared SNS conversations and friends.

Alternatively, those with a secure attachment style are more trusting and accepting of their romantic partner, as well as their flaws (Hazan \& Shaver, 1987). Returning to the same example used with anxious/ambivalent individuals, a secure individual may be less likely to develop hyperperceptions because they are more trusting of their partner. In theory, secure individuals would trust that their partner is not as interested in their SNS conversations and relationships as they are in their romantic relationships.

Individuals who have an avoidant attachment style, according to Hazan and Shaver (1987), believe that love is not made to last forever, and see the scenario described above as their partner moving on (a part of life and nothing more). Using the same example described in the previous 
two situations, it is possible that an avoidant individual would develop hyperperceptions regarding their partner's SNS interactions and relationships because they do not believe that they are meant to be with them forever. Avoidant individuals may perceive that their time with their partner is coming to a close, or could be, and therefore they develop hyperperceptions based off of this. Depending on the attachment style an individual has, hyperperception effects and whether or not they occur can be drastically different. While each situation is also unique, this example offers a glimpse into what it might mean to develop hyperpersonal thoughts depending on the attachment style that one has.

The potential for attachment style and hyperperception effects to be connected is what sparked this research. Based on the literature to date, we believe that there is enough evidence to investigate this potential connection. From this, we pose the research question:

RQ1: Does an individual's attachment style affect the extent to which they develop "hyperperceptions" of their partner's relationships with other people according to what they observe on Facebook?

\section{Method}

\section{Participants}

67 people participated in this study. There were 16 men $(23.9 \%), 49$ women $(73.1 \%), 1$ transgender individual (1.5\%), and 1 who did not indicate their gender (1.5\%). Their ages ranged from 18 to $42(M=23.57, S D=4.405)$. Participants were undergraduate communication students recruited from a university in the Pacific North West and another university in the Midwest. Students were informed of the survey opportunity upon a recruiter visiting their classroom and informing them of the research opportunity, as well as the risks involved with participating. In 
order to participate, students had to be in a romantic relationship at the time of the study and be a current Facebook user. In exchange for the students' participation, extra credit was awarded to them in their communication course.

\section{Materials}

Participants needed to have an actively used Facebook account in order to take part in this study, as well as a partner who had a Facebook account of their own that was used frequently. Participants needed internet access and either a mobile phone, tablet, or computer to take the survey online. Participants also needed an email account in order to send their partner a followup survey to the one they took, however, this was not required for the survey to be completed. In addition, this study in which participants chose to be a part of was an Institutional Review Board (IRB) approved study.

\section{Procedure}

In order to gauge if and how participant attachment styles led to hyperperceptions, this study implemented a 71-question online survey through Qualtrics to examine observations and perceptions around their partner's interactions on Facebook. After reading and consenting to participate in the study, participants were asked questions about their observations regarding their partner's interactions with three different people on Facebook; someone they perceive their partner to be very close to (person 1), someone they perceive their partner to be moderately close

to (person 2), and someone they perceive their partner to not be close to at all (person 3). These questions addressed how close participants felt their partner was to the three individuals, how much the participant had interacted with the three individuals (both online and offline), how satisfied the participant was in their romantic relationship with their partner, and their attachment 
style. Upon completion of the survey, students were asked to copy and paste a word template into an email to their significant other, as well as fill in their own name and their partner's name when appropriate.

\section{Measures}

A Qualtrics survey was distributed to participants for data collection. There were two variables measured in this study; one independent variable and one dependent variable. The independent variable in this study was attachment style, and was measured through a multiplechoice, categorical question response in the Qualtrics survey, with the attachment style measure coming from Hazan and Shaver (1987). The question used for measurement asked participants to read three self-descriptions and then choose the single alternative that best describes how they feel in romantic relationships. There were three multiple choice answers to choose from in response to the question, with each response indicating they had either an anxious/ambivalent attachment style, a secure attachment style, or an avoidant attachment style. If a participant selected, "I am somewhat uncomfortable being close to others; I find it difficult to trust them completely, difficult to allow myself to depend on them. I am nervous when anyone gets too close, and often, others want me to be more intimate than I feel comfortable being.," as their choice, they indicated that they have an anxious/ambivalent attachment style (Hazan \& Shaver, 1987). If a participant selected, "I find it relatively easy to get close to others and am comfortable depending on them and having them depend on me. I don't worry about being abandoned or about someone getting too close to me.," as their choice, they indicated that they have a secure attachment style (Hazan \& Shaver, 1987). If a participant selected, "I find that others are reluctant to get as close as I would like. I often worry that my partner doesn't really love me or won't want to stay with me. I want to get very close to my partner, and this sometimes scares 
people away.," as their choice, they indicated that they have an avoidant attachment style (Hazan \& Shaver, 1987).

The dependent variable in this study was the occurrence of hyperperceptions/hyperperception effects. This variable was measured through a multiple-choice question response, developed from Spottswood and Carpenter (Under Review). Participants responded to the question, "When [Person 1, 2, or 3] comments on my partner's Facebook posts, it seems like they really know my partner" by selecting one of seven multiple choice answers. The multiple-choice answers available were, "Strongly Disagree (1), Disagree (2), Slightly Disagree (3), Neither Agree Nor Disagree (4), Slightly Agree (5), Agree (6), Strongly Agree (7)."

\section{Results}

Bivariate analysis, specifically one-way ANOVA tests, were conducted by focusing on the different responses to a specific question from the survey. The question focused on was, "When [Person 1, 2, or 3] comments on my partner's Facebook posts, it seems like they really know my partner.” Participant's responses were analyzed for hyperperceptions through a one-way ANOVA test. The one-way ANOVA tests was conducted through the analyzation software program, IMB SPSS Statistics. The variables being tested through one-way ANOVA test were attachment style (independent variable), and the responses to the question, "When [Person 1, 2, or 3] comments on my partner's Facebook posts, it seems like they really know my partner" (dependent variable). All attachment styles were tested in regards to their responses for Person 1, 2 , and 3 . 
One-way ANOVA testing was used in this study because the independent variable (attachment style) is categorical, in that participants may only choose anxious/ambivalent, secure, or avoidant attachment styles. In addition, the dependent variable in this study (responses to the question, "When [Person 1, 2, or 3] comments on my partner's Facebook posts, it seems like they really know my partner") is continuous. With one categorical independent variable (that has multiple levels to it) as well as a continuous dependent variable, it was determined that oneway ANOVA tests would be the correct measures to use in this study. Additionally, the measures used to test for hyperperceptions (attachment style and responses to the question, "When [Person 1, 2, or 3] comments on my partner's Facebook posts, it seems like they really know my partner") were the best way to test for hyperperceptions for a multitude of reasons. Attachment style was one of the two main areas of interest in this study, and therefore needed to be considered to have an impact on the results, as well as the individual responses. Finally, the responses to the question, "When [Person 1, 2, or 3] comments on my partner's Facebook posts, it seems like they really know my partner," was important to measure in this study because it signified a potential overattribution of relationships from the participant's perspective; it would be very difficult to know if two individual's were close based on SNS observations from small posts or messages. Now, we will address what we found from the one-way ANOVA tests and data collection.

Analysis revealed that the anxious/ambivalent attachment style and the perception that one's significant other and Person 1 were close based on when Person 1 commented on their Facebook had a strong relationship, $F(1,18)=10.454, p=.005$, as shown in table 1 . This stayed consistent, as analysis further showed participants with the anxious/ambivalent attachment style and their perception that their significant other and Person 2 were close based on when Person 2 
commented on their partner's Facebook had a strong relationship, $F(1,18)=5.513, p=.031$, as shown in table 1. However, anxious/ambivalent attachment style and the perception that one's significant other and Person 3 were close based on when Person 3 commented on their Facebook did not have any relationship, $F(1,18)=4.007, p=.061$, as shown in table 1 , as compared to Person 1 and 2 (which had strong relationships).

Looking at the secure attachment style, analysis also showed the secure attachment style and the perception that one's significant other and Person 1 were close based on when Person 1 commented on their Facebook had strong relationships, $F(1,41)=7.159, p=.011$, as shown in table 1. This pattern stayed consistent with Person 2, as the secure attachment style and the perception that one's significant other and Person 2 were close based on when Person 2 commented on their Facebook had strong relationships, $F(1,41)=6.458, p=.015$, as shown in table 1. However, similar to Person 3 in the anxious/ambivalent attachment style one-way ANOVA tests, secure attachment style and the perception that one's significant other and Person 3 were close based on when Person 3 commented on their Facebook did not have any relationship, $F(1,41)=2.473, p=.124$, as shown in table 1 .

Finally, one-way ANOVA tests regarding the avoidant attachment style revealed that the avoidant attachment style and the perception that one's significant other and Person 1 were close based on when Person 1 commented on their Facebook had a strong relationship, $F(1,5)=$ $17.500, p=.009$, as shown in table 1 . Unlike the anxious/ambivalent and secure attachment styles, however, one-way ANOVA tests revealed that the avoidant attachment style and the perception that one's significant other and Person 2 were close based on when Person 2 commented on their Facebook had no relationship, $F(1,5)=3.967, p=.103$, as shown in table 1 . This pattern continued with Person 3, as one-way ANOVA tests revealed that the avoidant 
attachment style and the perception that one's significant other and Person 3 were close based on when Person 3 commented on their Facebook had no relationship, $F(1,5)=1.984, p=.218$, as shown in table 1.

\section{Discussion}

This study was conducted with the purpose to see if an individual's attachment style might be related to the likelihood someone would hyperperceive their romantic partner's interactions with another person on a SNS. We examined individuals' perceptions surrounding their partner's relationships with others, in addition to their attachment style, to look for an answer. SNSs played a key role in testing for hyperperception effects/occurrences, as Spottswood and Carpenter's (Under Review) hyperperception model focuses on relational exaggerations made from observations on SNS platforms. SNSs served as the channel for senders to communicate messages and romantic partners to make observations about those messages (Spottswood \& Carpenter, Under Review). In utilizing Spottswood and Carpenter's (Under Review) hyperperception model, in conjunction with pre-existing research on attachment styles, communication literature and research were advanced in several different ways. These advancements include exploring new research regarding attachment styles and hyperperceptions, furthering research on romantic couples, perceptions of relationships in our own lives, the overattribution of these perceptions regarding relationships, as well as opening up new avenues for further research and exploration.

As stated earlier, this study explored how attachment style(s) may affect the extent to which participants develop hyperperceptions of their partner's interactions with other people on SNSs. One-way ANOVA tests showed that there was a relationship between attachment style and hyperperceptions of a partner's relationship with others. The extent of that relationship 
across all attachment styles varied, and the degree to which hyperperceptions occurred changed depending on the person that was being examined (e.g., someone that was very close to a participant's partner, moderately close, and not close at all). The relationship between the different attachment styles and the likelihood to observe hyperperceptions effects will be discussed in the following order: anxious/ambivalent, secure, and avoidant.

The anxious/ambivalent attachment style, as explained by Hazan and Shaver (1987), is an attachment style that leaves individuals with high levels of sexual attraction, jealousy, and the need to be wanted by their romantic partner. The anxious/ambivalent attachment style may contribute to hyperperception developments due to the jealousy paradigm of the attachment style. If an anxious/ambivalent person perceives that their partner is close to another individual based on observing SNS behavior, even if not true, anxious/ambivalent people are already more likely to become jealous than other attachment styles. This jealousy may lead to the belief that their partner is closer to someone than they really are, thus creating a hyperperception of the relationship. In this study, we found that people with an anxious/ambivalent attachment style do develop hyperperceptions of their partner's relationship with others through SNS use (specifically with Person 1 and Person 2; one-way ANOVA tests found nothing regarding Person 3). This means that participants with an anxious/ambivalent attachment style did develop hyperperception effects when stating whether or not Person 1 and Person 2 really knew their partner, but not Person 3. For example, participants with the anxious/ambivalent attachment style may feel as though their partner and Person 1/Person 2 really know one and other well, when it is possible they do not know each other well at all. This more than likely prompts anxious/ambivalent people to continue using SNSs as a way to survey their partner's recent activity on platforms, but even closer and more frequently. These findings help explain 
preexisting research discussed in this study, such as Marshall et al.'s (2012). Many college students using SNSs as a means to survey their partner's activity with others could be a sign of distrust or jealousy with another's partner, and the need for validation that they are wanted by their romantic partner in their relationship. Fleuriet et al.'s (2014) research may also be explained through these findings, as they pose CMC can lead to ambiguity and even jealousy through nonverbal cues. Due to anxious/ambivalent people being much more likely to develop feelings of jealousy, this connection could explain Fleuriet et al.'s (2014) statements.

The secure attachment style poses that an individuals are more able to accept their romantic partner, despite their faults, and find that being happy, friendly, and trusting are the most notable factors when experiencing love (Hazan \& Shaver, 1987). This suggests that secure individuals are less likely to develop hyperperceptions based on observations of their partners other relationships on SNS platforms. Despite this, individuals with a secure attachment style still revealed a relationship between their attachment style and hyperperceptions (specifically with Person 1 and Person 2; one-way ANOVA tests found nothing regarding with Person 3). This means that participants with a secure attachment style did develop hyperperception effects when stating whether or not Person 1 and Person 2 really knew their partner, but not Person 3 . For example, participants with the secure attachment style may feel as though their partner and Person 1/Person 2 really know one and other well, when it is possible they do not know each other well at all. This differs from the research by Hazan and Shaver (1987) in that secure individuals may also develop hyperperceptions about their partner's relationships with others. While these hyperperceptions surrounding their romantic partner's other relationships may not be negative, this still signals actions that are more out of the norm for secure individuals. The occurrence of these hyperperceptions in secure individuals may occur for a variety of reasons. 
One possible explanation is that while hyperperceptions effects may occur through individuals with a secure attachment style, it does not necessarily mean that those hyperperceptions will lead to feelings of jealousy. Individuals may make over-attributions of their partner's SNS interactions with others, but those over-attributions do not mean that their perceptions will create feelings of jealousy or negativity that will, in turn, have a harmful impact on the relationship. Alternatively, another explanation may simply be that while secure individuals are less likely to develop hyperperception effects, they are not exempt or excluded from groups that do develop them.

Individuals who have an avoidant attachment style typically do not believe in fairy-tale love as seen in films and books, that love is not something to commonly last for a lifetime, and find themselves afraid of becoming close and intimate (Hazan \& Shaver, 1987). This attachment style can impact the development of hyperperceptions in many different ways. For example, avoidant individuals seeing their partner interact with another on SNSs may lead them to believe that their time with their romantic partner is coming to a close; love is not meant to last forever. It may also worry the avoidant individual, as they find themselves becoming closer to their romantic partner and opening themselves up to be hurt/disappointed if their relationship does last forever. In this study, avoidant individuals revealed a relationship between their attachment style and hyperperceptions (strong relationships were found with Person 1 and the Avoidant Attachment style; one-way ANOVA tests found nothing in regards to Person 2 or Person 3). This means that participants with an avoidant attachment style did develop hyperperception effects when stating whether or not Person 1 really knew their partner, but not Person 2 or Person 3. For example, participants with the avoidant attachment style may feel as though their partner and Person 1 really know one and other well, when it is possible they do not know each other well at 
all. The relationships found between hyperperception development alongside attachment style were different with avoidant individuals than anxious/ambivalent and secure individuals. This finding might suggest that avoidant individuals with an avoidant attachment style are not as likely to develop hyperperception effects around their partner's SNS interactions unless they perceive their partner and the receiver of the messages really know one and other. These findings could again help explain previous research such as Fleuriet et al.'s (2014). As Fleuriet et al. (2014) explains, nonverbal communication can lead to uncertainty of where one stands in a relationship. Avoidant individuals may be concerned about where they stand in their relationship with the views their attachment style poses for them, leading to feelings of distance and their own uncertainty about the relationship.

\section{Future Research}

The results of this study open up new avenues for research and exploration in communication disciplines, such as how hyperperceptions and the model can be used to explore how SNS use effects people's relationships (both romantic and platonic relationships). Future studies expanding upon this research may consider including the romantic partner's perceptions about their own relationships; the same relationships that participants described. Comparing the observer's perceptions and their romantic partner's perceptions of the latter's SNS interactions and relationships would further uncover the relationship between hyperperception effects with attachment styles. This extension study could distribute a similar survey that was used in this study to participants, asking various questions about perceptions/observations pertaining to their romantic partner's relationships on SNSs. This survey would be designed to also test if participants have hyperperceptions occurring form their SNS observations, as well as the attachment style that they have. Toward the end of this survey, researchers could ask participants 
to send an alternative survey to their romantic partners that gauges if they find their relationships to be as strong as the participant did. In addition, this research could include assessments of both romantic partner attachment styles, while also asking them to identify their partner's attachment style to the best of their ability. This would help confirm whether or not their attachment style is accurate according to their partner's perceptions. Based on the research done in this study, this one direction that future research should look to expand upon. Gathering information and data from the romantic partner could both confirm results found in this study, as well as expand upon them with new data that leads to new avenues of exploration.

\section{Limitations}

There are several areas in which this research was confined and limited. These areas of limitation could be improved in future studies to gather more generalizable data. First, a larger sample group could be used to gather data for analysis. With this study, a small sample size was tested with one-way ANOVA to look for a relationship between attachment style and hyperperceptions. While relationships between the two were found were found, the sample sized is not large enough to be able to generalize our results/findings to the public as a whole, and, therefore, more research must be conducted to find more generalizable results.

In addition to this, it is possible that the means used to measure hyperperceptions in this study may not have measured hyperperceptions at all. The participant's perceptions (the results of this study) may have been accurate, or potentially hyper, and not at all hyperperceptions. The questions used to gauge hyperperception effects in this study ("When [Person 1, 2, or 3] comments on my partner's Facebook posts, it seems like they really know my partner”) is a step in the right direction for potentially discovering the development of hyperperception effects, as well as on track with the conceptualization of the theoretical process, but more research should 
be conducted to ensure the hyperperception model (and the means in which it is measured) are accurate/correct. Furthermore, more randomized sampling could be used in order to create a more accurate representation of the general population. In this study, participants were mainly female, with over two-thirds of the results being dominated by women. Having more male and transgender/other identifiable genders represented in future research may lead to more accurate and generalizable findings.

Finally, as is difficult with all quantitative research, it is difficult to gauge if participants were accurately representing themselves and their beliefs in their responses to the survey. Participants may have been more honest or dishonest based on how they wanted to perceive themselves in their relationship, as well as with their perceptions of their partner's own relationships outside of the one that they shared with the participant. Finding ways to minimalize this margin of error would, in turn, help create stronger results.

\section{Conclusion}

Attachment style and hyperperceptions share a relationship between one and other in this study. However, additional testing is needed in relation to the two in order to see if these existing relationships are significant to a larger sample of people (a sample that can be generalized to the public). For now, this study has shown that there is a connection between attachment styles being predictive of hyperperceptions in romantic relationships. These hyperperceptions and their relationships to attachment style change depending on the perceived closeness of the individual interacting with another's partner. This study offers exciting new developments in the advancement of interpersonal communication, as well as perceptions of relationships from an individual's viewpoint. 


\section{References}

Dainton M, Stokes A. College students' romantic relationships on Facebook: Linking gratification for maintenance to Facebook maintenance activity and the experience of jealousy. Communication Quarterly 2015; 63: 365-83

Fleuriet C, Cole M, Guerrero LK. Exploring Facebook: Attachment style and nonverbal message characteristics as predictors of anticipated emotional reactions to Facebook postings. Journal of Nonverbal Behavior 2014; 38:429-450.

Fox, J., Warber, K. M., \& Makstaller, D. C. (2013). The role of Facebook in romantic relationship development: An exploration of Knapp's relational stage model. Journal of Social and Personal Relationships, 30, 771-794. doi: 10.1177/0265407512468370

Hazan, C., \& Shaver, P. (1987). Romantic love conceptualized as an attachment process. Journal of Personality and Social Psychology, 52(3), 511-524. doi:10.1037/0022-3514.52.3.511

Marshall TC, Bejanyan K, Castro GD, Lee RA . Attachment styles as predictors of Facebookrelated jealousy and surveillance in romantic relationships. Personal Relationships 2012; 20:1-22.

Muise, A., Christofides, E., \& Desmarais, S. (2009). More information than you ever wanted: Does Facebook bring out the green-eyed monster of jealousy? CyberPsychology \& Behavior, 12, 441-444. doi: 10.1089/cpb.2008.0263

Muise, A., Christofides, E., \& Desmarais, S. (2013). “Creeping” or just information seeking? Gender differences in partner monitoring in response to jealousy on Facebook. Personal Relationships, 21(1), 35-50. doi:10.1111/pere.12014 
Simpson, J. A. (1990). Influence of attachment styles on romantic relationships. Journal of Personality and Social Psychology, 59(5), 971-980.

Spottswood EL, Hancock JT. The positivity bias and prosocial deception on facebook.

Computers in Human Behavior 2016; 65:252-9.

Spottswood, E., \& Carpenter, C. (n.d.). Hyperperception_A Fresh Take. Retrieved October 11, 2018.

Spottswood, E., \& Carpenter, C. (n.d.). Hyperperception Jealousy General Couples Study. Retrieved October 11, 2018.

Utz S. The function of self-disclosure on social network sites: Not only intimate, but also positive and entertaining self-disclosures increase the feeling of connection. Computers in Human Behavior 2015; 45:1-10.

Walther JB. Computer-mediated communication: Impersonal, interpersonal, and hyperpersonal interaction. Communication research 1996; 23:3-43. 


\section{Appendix A}

\section{Attachment Styles and Hyperperception One-Way ANOVA Tests}

Of the three attachment styles, the anxious/ambivalent attachment style showed the strongest statistical significance between attachment style and hyperperceptions when examining Person 1, $F(1,18)=10.454, p=.005$. The next strongest statistical significance was found between attachment style and hyperperceptions was the avoidant attachment style regarding Person 1 as well, $F(1,5)=17.500, p=.009$. Finally, third strongest statistical significance between attachment style and hyperperceptions was the secure attachment style regarding Person 1 again, $F(1,41)=7.159, p=.011$.

The avoidant attachment style did not show statistical significance with Person 2, and therefore no relationship could be found/made. All three attachment styles did not show statistical significance regarding Person 3 in this study, and, therefore, no relationships could be made based on this.

\section{Table 1}

\begin{tabular}{|c|c|c|c|}
\hline Attachme & Person 1, 2, and $3 A N$ & VA Test & orted " $F$ " \\
\hline & Anxious/Ambivalent & Secure & Avoidant \\
\hline Person 1 & $10.454 * *$ & $.7 .159 *$ & $17.500 * *$ \\
\hline Person 2 & $5.513 *$ & $6.458 *$ & 3.967 \\
\hline Person 3 & .4 .007 & 2.473 & 1.984 \\
\hline Note. *. & gnificant at the 0.05 & vel (2-ta & \\
\hline & significant at the 0 . & vel $(2$ & \\
\hline
\end{tabular}




\section{Appendix B}

\section{Qualtrics Survey Distributed to Participants}

This survey, in its entirety, was distributed to participants who were a part of this study. It was used to collect data, as well as compare differences in findings between attachment styles. In this survey, the independent variable was a participant's attachment style, and was measured through participants choosing from one of three descriptions that best matched their feelings when in a romantic relationship. The descriptions to choose from were, " The dependent variable in this study was a participant's response to the question, "When [Person 1, 2, or 3] comments on my partner's Facebook posts, it seems like they really know my partner," and was indicated by selecting one of seven multiple choice answers. The multiple-choice answers available were, “Strongly Disagree (1), Disagree (2), Slightly Disagree (3), Neither Agree Nor Disagree (4), Slightly Agree (5), Agree (6), Strongly Agree (7).”

The survey is integral to the entirety of this study, as it was the means for collecting data in this study, as well as what lead to our results and areas of interest for future research.

\section{Qualtrics Survey:}

The Portland State University

Consent to Participate in Research Couples Facebook Study

Version date of consent

Introduction 
You are being asked to participate in a research study that is being done by Prof. Erin Spottswood, who is the Principal Investigator, from the Department of Communication at Portland State University in Portland, Oregon and Prof. Chris Carpenter of Western Illinois University in Macomb, IL. This research is studying couples' perceptions of each other's Facebook friends.

You are being asked to participate in this study because you use Facebook and are in a romantic relationship with someone who uses Facebook.

This form will explain the research study, and will also explain the possible risks as well as the possible benefits to you. We encourage you to talk with your family and friends before you decide to take part in this research study. If you have any questions, please ask one of the study investigators.

What will happen if I decide to participate?

If you agree to participate, the following things will happen:

You will be asked to choose three of your romantic partner's Facebook friends and answer some questions about the interactions your partner has with those people. You will also be asked at the end of the survey to email your partner a request to complete a complimentary study about those same people. You will both also learn what your romantic relationship attachment style is so that you can compare. No part of the study is experimental, it is all online survey.

How long will I be in this study? 15 minutes

Participation in this study will take a total of about 15 minutes in one session. 
What are the risks or side effects of being in this study?

There are no known risks to participation in this study. However, there are risks of stress, emotional distress, inconvenience and possible loss of privacy and confidentiality associated with participating in research studies in general. If you have any questions or concerns about your participation in this study please contact the lead researcher or the PSU IRB review board.

Your participation in this study will in no way affect your grade or academic standing at Portland State University. In addition, your grades and standing at Portland State University will not be affected by choosing not to participate or by not completing the survey.

You will be responding to potentially private data about your perceptions of your romantic partner and we will be collecting your name for the purpose of linking your survey to your partners. The data security procedures the researchers will follow to protect your privacy are described below.

For more information about risks and discomforts, ask the investigator.

What are the benefits to being in this study?

You and your romantic partner will both learn about your attachment styles. That may give you insight into ways to improve your romantic relationships.

How will my information be kept confidential?

We will take measures to protect the security of all your personal information, but we cannot guarantee confidentiality of all study data. 
The researchers will keep the data in a password protected online database that only the two researchers have access to. Once the data has been matched, identifying information will be erased.

Information contained in your study records is used by study staff. The Portland State University Institutional Review Board (IRB) that oversees human subject research and/or other entities may be permitted to access your records, and there may be times when we are required by law to share your information. It is the investigator's legal obligation to report child abuse, child neglect, elder abuse, harm to self or others or any life-threatening situation to the appropriate authorities, and; therefore, your confidentiality will not be maintained.

Your name will not be used in any published reports about this study.

Will I be paid for taking part in this study?

If both you and your partner complete the assigned surveys, you will be entered into a chance to win $\$ 30$ in a drawing.

Can I stop being in the study once I begin?

Your participation in this study is completely voluntary. You have the right to choose not to participate or to withdraw your participation at any point in this study without penalty or loss of benefits to which you are otherwise entitled.

Whom can I call with questions or complaints about this study?

If you have any questions, concerns or complaints at any time about the research study, Prof. Spottswood, or her associates will be glad to answer them at 503.725.5810. 
If you need to contact someone after business hours or on weekends, please call 503.725.5810 and askfor Dr. Spottswood.

Whom can I call with questions about my rights as a research participant?

If you have questions regarding your rights as a research participant, you may call the PSU Office for Research Integrity at (503) 725-2227 or 1(877) 480-4400. The ORI is the office that supports the PSU Institutional Review Board (IRB). The IRB is a group of people from PSU and the community who provide independent oversight of safety and ethical issues related to research involving human participants. For more information, you may also access the IRB website at https://sites.google.com/a/pdx.edu/research/integrity.

Please print out a copy of the consent form for your future reference.

\section{CONSENT}

You are making a decision whether to participate in this study. By clicking "accept" at the end of this form, you are consenting to participate in this survey. IF you do not consent, please click "decline” to navigate away from the survey.]

(If Participants select "Accept," they begin taking the survey below)

Thank you for participating in our survey 
At the end of the survey, we'll provide you with information about what your attachment style is. Then if your partner completes the short survey, you can find out what kind of attachment style he or she is too.

We are interested in how people perceive each other's Facebook friends.

Please open your partner's Facebook profile page in another browser window or tab. Click on your partner's "Friends" list. We're going to need you to choose three people from this list and answer the same set of questions about each one. All three need to be:

1. An adult

2. The same sex as you are

3. Not a family member of you or your partner.

At the end of the survey we're going to ask you to send an email to your partner with the names of all three of these people so that they can answer just a few questions about them. So make sure it is three names you're willing to ask your partner to answer a few questions about

The first person you choose needs to be someone who fits those three rules and is someone you perceive your partner to be very close to or as close as possible while still fitting these three rules. Please type that person's initials here: [Initials would be typed here] 
The second person you choose needs to be someone who fits those three rules and is someone you perceive your partner to be of moderate closeness. Please type that person's initials here: [Initials would be typed here]

The third person you choose needs to be someone who fits those three rules and is someone you perceive your partner to be not at all close with, perhaps someone they barely know. Please type that person's initials here: [Initials would be typed here]

Now, consider the first person you chose, here are their initials [Initials from Person 1 appear here]

Please answer the following questions with that person in mind

Please indicate the extent to which the following statements accurately reflect the interactions you see your partner having with [Person 1]

First, how often do you see your partner interacting with [Person 1] on Facebook, including commenting on statuses and pictures, sharing on each other's timelines (walls), and any other interactions on Facebook?

1 - Never

2 - Occasionally

3 - Sometimes

4 - Regularly

5 - Often 
6 - Constantly

Their Facebook interactions look like they are having fun together

1 - Strongly Disagree

2 - Disagree

3 - Slightly Disagree

4 - Neither Agree nor Disagree

5 - Slightly Agree

6 - Agree

7 - Strongly Agree

Their Facebook interactions make it seem like they really seem to understand each other

1 - Strongly Disagree

2 - Disagree

3 - Slightly Disagree

4 - Neither Agree nor Disagree

5 - Slightly Agree

6 - Agree

7 - Strongly Agree

My partner seems really interested in the interactions she or he has on Facebook with

\section{[Person 1]}

1 - Strongly Disagree

2 - Disagree

3 - Slightly Disagree

4 - Neither Agree nor Disagree 
5 - Slightly Agree

6 - Agree

7 - Strongly Agree

When [Person 1] comments on my partner's Facebook posts, it seems like they really know my partner

1 - Strongly Disagree

2 - Disagree

3 - Slightly Disagree

4 - Neither Agree nor Disagree

5 - Slightly Agree

6 - Agree

7 - Strongly Agree

Their Facebook interactions look like they have a lot of the same interests

1 - Strongly Disagree

2 - Disagree

3 - Slightly Disagree

4 - Neither Agree nor Disagree

5 - Slightly Agree

6 - Agree

7 - Strongly Agree

Please answer the following questions by choosing which response best represents your impressions 


\section{Please indicate the extent to which you know [Person 1]}

1- I have never met [Person 1] offline (in real life)

$2-$

$3-$

$4-$

$5-$

6-

7- I have interacted with [Person 1] many times offline (in real life)

1- I have never seen my partner and [Person 1] interacting face-to-face

2

3

4

5

6

7- I have seen my partner interact with [Person 1] many times face-to-face

1- I have never seen my partner never talks with [Person 1] offline (in real life)

2

3

4

5

6 
7- I see my partner interact with [Person 1] all the time offline (in real life)

1- I do not know how my partner does/would act around [Person 1] offline (in real life)

2

3

4

5

6

7- I know exactly how my partner does/would act around [Person 1] offline (in real life)

Look at the pairs of circles below. For each pair, imagine the circle on the left represents your partner and the circle on the right represents [Person 1]. Choose a pair of circles that best describes their relationship.

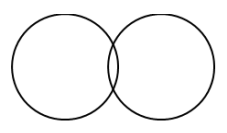

1

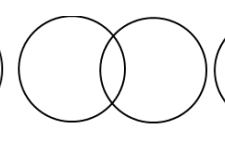

2

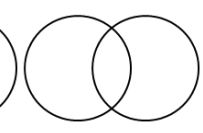

3

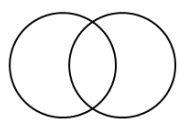

4

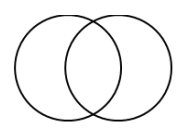

5

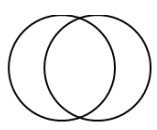

6

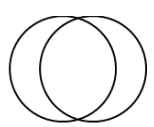

7

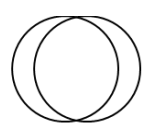

8

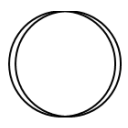

9

Consider the interactions you have seen between your partner and [Person 1] on Facebook.

Use the following measures to indicate your perceptions of their interactions on Facebook.

Distant 1234567 Close

Detached 1234567 Engaging

Nonexpressive 1234567 Expressive

Unfriendly 1234567 Friendly

Cold 1234567 Warm 
Now, consider the second person you chose, here are their initials

[Initials from Person 2 appear here]

Please answer the following questions with that person in mind

Please indicate the extent to which the following statements accurately reflect the interactions you see your partner having with [Person 2]

First, how often do you see your partner interacting with [Person 2] on Facebook, including commenting on statuses and pictures, sharing on each other's timelines (walls), and any other interactions on Facebook?

1 - Never

2 - Occasionally

3 - Sometimes

4 - Regularly

5 - Often

6 - Constantly

Please indicate the extent to which the following statements accurately reflect the interactions you see your partner having with [Person 2]

1 - Strongly Disagree

2 - Disagree

3 - Slightly Disagree

4 - Neither Agree nor Disagree 
5 - Slightly Agree

6 - Agree

7 - Strongly Agree

Their Facebook interactions look like they are having fun together

1 - Strongly Disagree

2 - Disagree

3 - Slightly Disagree

4 - Neither Agree nor Disagree

5 - Slightly Agree

6 - Agree

7 - Strongly Agree

Their Facebook interactions make it seem like they really seem to understand each other

1 - Strongly Disagree

2 - Disagree

3 - Slightly Disagree

4 - Neither Agree nor Disagree

5 - Slightly Agree

6 - Agree

7 - Strongly Agree

My partner seems really interested in the interactions she or he has on Facebook with [Person 2]

1 - Strongly Disagree

2 - Disagree 
3 - Slightly Disagree

4 - Neither Agree nor Disagree

5 - Slightly Agree

6 - Agree

7 - Strongly Agree

When [Person 2] comments on my partner's Facebook posts, it seems like they really know my partner

1 - Strongly Disagree

2 - Disagree

3 - Slightly Disagree

4 - Neither Agree nor Disagree

5 - Slightly Agree

6 - Agree

7 - Strongly Agree

Their Facebook interactions look like they have a lot of the same interests

1 - Strongly Disagree

2 - Disagree

3 - Slightly Disagree

4 - Neither Agree nor Disagree

5 - Slightly Agree

6 - Agree

7 - Strongly Agree 
Please answer the following questions by choosing which response best represents your impressions

Please indicate the extent to which you know [Person 2]

1- I have never met [Person 2] offline (in real life)

$2-$

$3-$

$4-$

$5-$

$6-$

7- I have interacted with [Person 2] many times offline (in real life)

1- I have never seen my partner and [Person 2] interacting face-to-face

2

3

4

5

6

7- I have seen my partner interact with [Person 2] many times face-to-face

1- I have never seen my partner never talks with [Person 2] offline (in real life)

2

3 
7- I see my partner interact with [Person 2] all the time offline (in real life)

1- I do not know how my partner does/ would act around [Person 2] offline (in real life)

2

3

4

5

6

7- I know exactly how my partner does/ would act around [Person 2] offline (in real life)

Look at the pairs of circles below. For each pair, imagine the circle on the left represents your partner and the circle on the right represents [Person 2]. Choose a pair of circles that best describes their relationship.

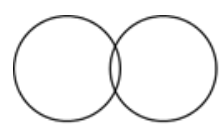

1

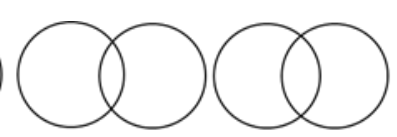

2

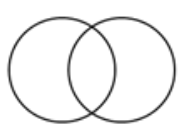

4

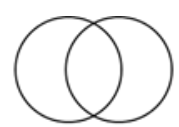

5

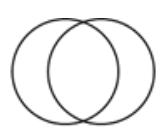

6

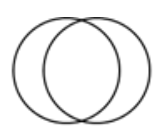

7

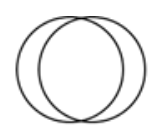

8

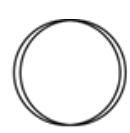

9

Consider the interactions you have seen between your partner and [Person 2] on Facebook. Use the following measures to indicate your perceptions of their interactions on Facebook.

Distant 1234567 Close

Detached 1234567 Engaging

Nonexpressive 1234567 Expressive 
Unfriendly 1234567 Friendly

Cold 1234567 Warm

Now, consider the (third) person you chose, here are their initials

[Initials from Person 3 appear here]

Please answer the following questions with that person in mind

Please indicate the extent to which the following statements accurately reflect the interactions you see your partner having with [Person 3]

First, how often do you see your partner interacting with [Person 3] on Facebook, including commenting on statuses and pictures, sharing on each other's timelines (walls), and any other interactions on Facebook?

1 - Never

2 - Occasionally

3 - Sometimes

4 - Regularly

5 - Often

6 - Constantly

Please indicate the extent to which the following statements accurately reflect the interactions you see your partner having with [Person 3]

1 - Strongly Disagree

2 - Disagree 
3 - Slightly Disagree

4 - Neither Agree nor Disagree

5 - Slightly Agree

6 - Agree

7 - Strongly Agree

Their Facebook interactions look like they are having fun together

1 - Strongly Disagree

2 - Disagree

3 - Slightly Disagree

4 - Neither Agree nor Disagree

5 - Slightly Agree

6 - Agree

7 - Strongly Agree

Their Facebook interactions make it seem like they really seem to understand each other

1 - Strongly Disagree

2 - Disagree

3 - Slightly Disagree

4 - Neither Agree nor Disagree

5 - Slightly Agree

6 - Agree

7 - Strongly Agree

My partner seems really interested in the interactions she or he has on Facebook with [Person 3] 
1 - Strongly Disagree

2 - Disagree

3 - Slightly Disagree

4 - Neither Agree nor Disagree

5 - Slightly Agree

6 - Agree

7 - Strongly Agree

When [Person 3] comments on my partner's Facebook posts, it seems like they really know my partner

1 - Strongly Disagree

2 - Disagree

3 - Slightly Disagree

4 - Neither Agree nor Disagree

5 - Slightly Agree

6 - Agree

7 - Strongly Agree

Their Facebook interactions look like they have a lot of the same interests

1 - Strongly Disagree

2 - Disagree

3 - Slightly Disagree

4 - Neither Agree nor Disagree

5 - Slightly Agree

6 - Agree 
7 - Strongly Agree

Please answer the following questions by choosing which response best represents your impressions

\section{Please indicate the extent to which you know [Person 3]}

1- I have never met [Person 3] offline (in real life)

$2-$

3-

$4-$

$5-$

6-

7- I have interacted with [Person 3] many times offline (in real life)

1- I have never seen my partner and [Person 3] interacting face-to-face

2

3

4

5

6

7- I have seen my partner interact with [Person 3] many times face-to-face

1- I have never seen my partner never talks with [Person 3] offline (in real life) 
7- I see my partner interact with [Person 3] all the time offline (in real life)

1- I do not know how my partner does/ would act around [Person 3] offline (in real life)

7- I know exactly how my partner does/ would act around [Person 3] offline (in real life)

Look at the pairs of circles below. For each pair, imagine the circle on the left represents your partner and the circle on the right represents [Person 3]. Choose a pair of circles that best describes their relationship.

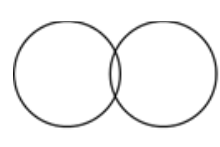

1

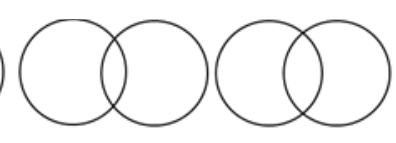

2

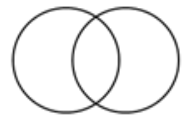

4

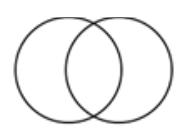

5

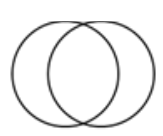

6

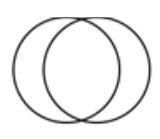

7

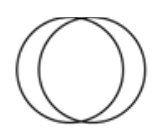

8

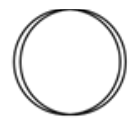

9

Consider the interactions you have seen between your partner and [Person 3] on Facebook. Use the following measures to indicate your perceptions of their interactions on Facebook. 
Distant 1234567 Close

Detached 1234567 Engaging

Nonexpressive 1234567 Expressive

Unfriendly 1234567 Friendly

Cold 1234567 Warm

Now, please think about your relationship with your partner and indicate how much you agree with the following statements

I feel satisfied with our relationship: Strongly Disagree 12345 Strongly Agree

My relationship is much better than other relationships: Strongly Disagree 12345 Strongly Agree

My relationship is close to ideal: Strongly Disagree 12345 Strongly Agree

Our relationship makes me very happy: Strongly Disagree 12345 Strongly Agree

Our relationship does a good job at fulfilling my needs for intimacy: Strongly Disagree 123

45 Strongly Agree

Please type your age, only type the two-digit number.

What gender do you identify as?

Female

Male

Trans* non-binary, two-spirit, genderqueer

Other, not listed 
Prefer not to answer

What is your full name?

What is your romantic partner's full name?

Please leave any comments you would like to make about the survey here:

Which class would you like to get extra credit for completing this survey?:

Next, before we measure your attachment style, we need you to email your partner the following by cutting and pasting the email below into your email. Don't forget to fill in the three names in the appropriate spot in the email. If you and your partner is drawn for the prize, you will be responsible for collecting the prize and for any taxes. The survey your partner will complete will be much shorter than your survey.

SUBJECT: Please take this survey for my Communication Class

Hey

I took a survey for extra credit in one of my Communication classes and answered some questions about three of your Facebook friends. I also found out what kind of relationship style I 
have. If you take a survey too you can find out your relationship style and we can compare.

We'll have a chance to win $\$ 30$

Please go to this link and answer the questions. It should be less than five minutes

The survey will ask you for the names of three of your Facebook friends; here are the names:

[Here you need to type in the three names]

[Link to the survey attached here]

Thanks!

[your name]

Did you send the email to your romantic partner with the three names in it?

Yes

No

Next, we'll find out what kind of attachment style you have and tell you what that means 
Read each of the three self-descriptions below and then choose the single alternative that best describes how you feel in romantic relationships or is nearest to the way you feel. (Note: The terms "close" and "intimate" refer to psychological or emotional closeness, not necessarily to sexual intimacy.)

1. I am somewhat uncomfortable being close to others; I find it difficult to trust them completely, difficult to allow myself to depend on them. I am nervous when anyone gets too close, and often, others want me to be more intimate than I feel comfortable being.

2. I find it relatively easy to get close to others and am comfortable depending on them and having them depend on me. I don't worry about being abandoned or about someone getting too close to me.

3. I find that others are reluctant to get as close as I would like. I often worry that my partner doesn't really love me or won't want to stay with me. I want to get very close to my partner, and this sometimes scares people away.

\section{[If they choose option 1]}

You chose the Avoidant Attachment Style

According to the seminal work on attachment style by Hazan and Shaver (1987):

"The avoidant lovers were characterized by fear of intimacy, emotional highs and lows, and jealousy... The avoidant lovers said the kind of head-over-heels romantic love depicted in novels 
and movies does not exist in real life, romantic love seldom lasts, and it is rare to find a person one can really fall in love with... avoidant subjects reported fear of closeness."

But remember that this classification only represents broad tendencies and may not necessarily reflect how you personally behave in relationships.

\section{[If they choose option 2]}

You chose the Secure Attachment Style

According to the seminal work on attachment style by Hazan and Shaver (1987):

"secure lovers described their most important love experience as especially happy, friendly, and trusting. They emphasized being able to accept and support their partner despite the partner's faults... secure lovers said that romantic feelings wax and wane but at times reach the intensity experienced at the start of the relationship and that in some relationships romantic love never fades... Secure respondents characterized their love experiences as friendly, happy, and trusting..."

But remember that this classification only represents broad tendencies and may not necessarily reflect how you personally behave in relationships.

\section{[If they choose option 3]}

You chose the Anxious/Ambivalent Attachment Style

According to the seminal work on attachment style by Hazan and Shaver (1987): 
“The anxious/ambivalent subjects experienced love as involving obsession, desire for reciprocation and union, emotional highs and lows, and extreme sexual attraction and jealousy... The anxious/ambivalent subjects claimed that it is easy to fall in love and that they frequently feel themselves beginning to fall... Anxious/ambivalent subjects described relationships marked by jealousy, emotional highs and lows, and desire for reciprocation."

But remember that this classification only represents broad tendencies and may not necessarily reflect how you personally behave in relationships."

Thank you for participating in our survey and emailing your partner for us! 